\title{
Epidemiological Investigation of Poultry Coccidiosis in and around Tarai Region of Uttarakhand
}

\author{
Sachin Pant ${ }^{1}$, Prakash Bhatt ${ }^{2}$, S. Shekhar ${ }^{3 *}$ and Gopal Krishna ${ }^{4}$ \\ ${ }^{1}$ Udham Singh Nagar Dairy Cooperative Limited, Khatima, Uttarakhand, India \\ ${ }^{2}$ Department of Veterinary Clinics, C.V.A.Sc., GBPUAT, Pantnagar, India \\ ${ }^{3}$ Veterinary Science, Krishi Vigyan Kendra, Koderma, Jharkhand, India \\ ${ }^{4}$ Department of Animal Husbandry, Himachal Pradesh, India
}

*Corresponding author

\section{A B S T R A C T}

\section{Keywords}

Epidemiological, Poultry coccidiosis,

Prevalence,

Management

Article Info

Accepted:

04 June 2018

Available Online:

10 July 2018
The present study aimed at epidemiological investigation of poultry coccidiosis in and around Tarai region of Uttarakhand. A total of 16 commercial poultry farms were screened and 9 were found positive for coccidiosis. Out of coccidiosis positive farms, 6 were broiler farms and 3 were layer farms. The overall prevalence of coccidiosis was $56.25 \%$, with $60 \%$ in broiler and $50 \%$ in layer flocks. The maximum prevalence was recorded during Aug-Sep (50\%) followed by June-July (33.3\%) and Dec-Jan (16.6\%) in broilers, while there was equal prevalence during June-July (33.3\%), Aug-Sep (33.3\%) and Oct-Nov $(33.3 \%)$ in layer farms. The management system mainly consisted of deep litter $(87.50 \%)$ followed by cage system $(12.50 \%)$. The identification of coccidian parasite was done by gross lesion site, oocyst morphology and coccimorph software. The most prevalent coccidian parasite identified was E. tenella $(66.6 \%)$ in both type of farms followed by $E$. maxima (50\%) and E. necatrix $(33.3 \%)$ in broiler, while in layers E. maxima $(33.3 \%)$ and 1 E. acervulina $(33.3 \%)$.

\section{Introduction}

Poultry is one of the most rapidly escalating segments of the agricultural sector in India. During the last four decades poultry industry has changed itself from backyard to a scientific industry. In recent years, livestock sector has emerged as one of the leading sector among Indian agriculture and within it; poultry farming has contributed substantially to the nation's economy (Rath et al., 2015). In fact, India is ranked $3^{\text {rd }}$ in egg and $6^{\text {th }}$ in meat production with an impressive growth rate of $6 \%$ and $12 \%$, respectively (Karthikeyan and Neduchezhian, 2013; FAO STAT, 2015), while the poultry population, egg and meat production was around 729.21 million, 69.73 billion and 2.68 million tonnes, respectively, with an annual per capita consumption of 58 eggs and 2.26 kilograms meat (BAHS, 2014). The tremendous growth of poultry industry in India is often hampered by various factors with poultry diseases being of pivotal importance (FAO, 1998; Rushton et al., 1999). 
Among the various diseases that affect the poultry sector coccidiosis is one of the most important affecting domestic fowl, turkey, geese, ducks, etc. (Hadipour et al., 2011) and is caused by the protozoa of phylum Apicomplexa, family Eimeriidae and in poultry primarily by species belonging to the genus Eimeria (Chauhan and Sushovan, 2003). There are about 1800 species of Eimeria that infects both animals and birds (Shirley, 1995), out of which ten species have been recorded from poultry in India with most common being $E$. tenella, $E$. necatrix, $E$. brunetti, E. maxima, E. acervulina, E. mitis and E. praecox. Among these, E. brunetti, E. maxima, $E$. necatrix and $E$. tenella are reported to be highly pathogenic, while $E$. acervulina, E. mitis and E. mivati are comparatively less pathogenic and least pathogenic are E. praecox and E. hagani (Bachaya et al., 2012). The diagnosis of Eimeria species is of foremost importance for a successful management of an outbreak of coccidiosis. In the field outbreak coccidia infection is diagnosed by presence of oocytes in the faeces and intestinal scrapings in which oocysts and endogenous developmental stages of parasites are detected. The infection caused by $E$. tenella and $E$. necatrix is diagnosed easily on the basis of lesion but infections of other species are difficult to diagnose. Under these circumstances, it is the need of the hours for the poultry industry to develop better knowledge of the etiology and population dynamics of mixed coccidia infections in commercial poultry farms for the control of coccidiosis, in order to survive the global competition.

\section{Materials and Methods}

For epidemiological investigation, a total of 16 commercial poultry farms were screened from different regions like Pantnagar, Khatima, Bareilly, Shantipuri, Khatima, Moradabad, Haldwani, Almora, Uttarkashi etc. for poultry coccidiosis based on history of poor weight gain, anaemia, mortality and voiding of blood stained faeces. Identification of different Eimeria species was based on the site of gross lesions, morphology of sporulated oocysts and by use of COCCIMORPH software. The faecal or intestinal samples of unsporulated oocysts were kept in $2.5 \%$ potassium dichromate solution till the sporulation occurred. After sporulation one to two drops were placed on a microscopic slide and covered with cover slip and then the morphology of sporulated oocysts were determined microscopically as described by Long and Reid (1982). COCCIMORPH software was used to identify the different Eimeria species which was downloaded from internet (http://www.coccidia.icb.usp.br/ coccimorph) and the photomicrographic images of the sporulated oocysts were uploaded and based on size, symmetry and internal structure different Eimeria species were identified. Post mortem examination of birds died due to coccidiosis was performed as per the procedure described by Conway and McKenzie (2007) to determine the site of gross lesion.

\section{Results and Discussion}

Out of total 16 poultry farms screened, 9 were confirmed to be suffering from different Eimeria species representing an overall prevalence of $56.25 \%$. The present study was supported by Bachaya et al., (2012) who reported the prevalence of $59.60 \%$ in Muzzafargarh region but was considerably higher from those recorded by Nikam et al., (2012) with an overall prevalence of $29.08 \%$ in Maharashtra, Sharma et al., (2013) with $39.58 \%$ in Jammu and Kashmir, Kala et al., (2013) with $16.54 \%$ in Bihar and Jadhav and Nikam (2014) in Gangapur and Vaijapur region of Aurangabad, Maharashtra with $36.07 \%$ and $35.90 \%$, respectively. The reason for the variation in prevalence can be 
attributed to the fact that in these reports random samples were collected from different farms, i.e. healthy as well as diseased farms, while in our study only those farms which were suspected to be suffering for coccidiosis were considered for examination. Based on the type of birds, 6 out of 10 broiler farms and 3 among 6 commercial layer farms were confirmed to be positive for coccidiosis with the prevalence of $60 \%$ and $50 \%$, respectively. Deo (1988), Kumar et al., (2013) and Kala et al., (2013) also found the prevalence to be higher in broilers as compared to layer birds. However, contrary to the present observations, Banu et al., (2009) and Jatau et al., (2012) recorded prevalence of coccidiosis to be higher in layer birds compared to broilers. Month wise prevalence of coccidiosis was higher during the monsoon season particularly during the months of July to September. The prevalence was recorded to be highest during August- September followed by June-July and equal in months of October- November and December- January with 44.4\%, 33.3\%, $11.11 \%$ and $11.11 \%$, respectively. Based on type of birds reared, in broilers there were 2 outbreaks reported during the months of JuneJuly $(33.3 \%), 3$ in August-September (50\%) and 1 during December- January (16.6\%) while in case of layer birds, there was one outbreak each during June- July (33.3\%), August- September (33.3\%) and OctoberNovember $(33.3 \%)$. This is due to the fact that at this time of the year environmental are conducive for transmission and sporulation of oocysts, resulting in higher cases (Sharma et al., 2013).

Management system in both broiler and layers mainly consisted of deep litter system. Out of the 10 broiler farms that were visited all of them had deep litter system of management $(100 \%)$, while in case of layer farms 4 among 6 (66.6\%) followed deep litter system including the 3 farms (75\%) that were positive for coccidiosis. Meanwhile, 2 layer farms
(33.3\%) used cage system of management. Singh and Meitei (2015) mentioned that in deep litter system due to litter pillage and crevices, the risk of infection increases. Thick layers of litter which is used to maximize the absorption, when gets wet it sticks to boots, utensils, shoes and vehicle and is thus transmitted from one farm to another (Chauhan and Sushovan, 2003 and Davou et al., 2015).

Using different methods like site of gross lesions, morphology of oocysts and by use of COCCIMORPH software different Eimeria species were identified in the coccidiosis affected farms. There were mixed infection in most of the broilers as well as in layer flocks. In coccidiosis affected broiler farms, E. tenella $(66.6 \%)$ was the most prevalent species followed by E. maxima (50\%) and E. necatrix (33.3\%), respectively. Likewise, in layer flocks also $E$. tenella has maximum prevalence $(66.6 \%)$ followed by E. maxima $(33.3 \%)$ and E. acervulina (33.3\%).

Hadipour et al., (2011), Bachaya et al., (2012), Amare et al., (2012), Dinka and Tolassa (2012), Kala et al., (2013) and Singh and Meitei (2015) also mentioned that $E$. tenella was the most prevalent species among all species. This might be due to high pathogenicity and predominant nature of $E$. tenella (Adhikari et al., 2008). However, Shirzad et al., (2011), Kumar et al., (2013) and Gharekhani et al., (2014) in their studies found $E$. acervulina to be the most predominant species, Jatau et al., (2012) recorded E. maxima to be the most prevalent species, while Molla and Ali (2015) observed $E$. brunetti to be the most common species in Ethiopia. The possible reason behind this difference could be the variability in virulence of Eimeria species in the birds housed under different management system and problem of drug resistance (Dinka and Tolassa, 2012) (Table 1-3). 
Table.1 Month-wise prevalence of poultry coccidiosis

\begin{tabular}{|c|c|c|c|c|c|c|}
\hline \multirow[t]{2}{*}{ Month } & \multicolumn{2}{|c|}{ Type of bird } & \multicolumn{2}{|c|}{ Age } & \multicolumn{2}{|c|}{ Infection } \\
\hline & Broiler & Layer & Broiler & Layer & Broiler & Layer \\
\hline June-July & 1 & 1 & $21 d$ & $36 d$ & E. tenella & E. tenella \\
\hline June-July & 1 & - & $19 d$ & - & $\begin{array}{l}\text { E. necatrix } \\
\text { E. tenella }\end{array}$ & - \\
\hline Aug-Sep & 1 & 1 & $40 \mathrm{~d}$ & $42 d$ & $\begin{array}{l}\text { E. maxima } \\
\text { E. tenella }\end{array}$ & $\begin{array}{c}\text { E. acervulina } \\
\text { E. maxima }\end{array}$ \\
\hline Aug-Sep & 1 & - & $13 d$ & - & E. maxima & - \\
\hline Aug- Sep & 1 & - & $22 d$ & - & E. tenella & - \\
\hline Oct-Nov & - & 1 & - & 24 weeks & - & E. acervulina \\
\hline Dec- Jan & 1 & - & $37 d$ & - & - & $\begin{array}{l}\text { E. tenella } \\
\text { E. maxima }\end{array}$ \\
\hline
\end{tabular}

Table.2 Mortality due to coccidiosis at affected broiler farms

\begin{tabular}{|l|c|}
\hline Farm Code & Mortality (\%) \\
\hline Farm B1 (Shantipuri, U.S. Nagar) & $18.8 \%$ \\
\hline Farm B2 (Haldwani) & $1.5 \%$ \\
\hline Farm B3(Almora) & $1.8 \%$ \\
\hline Farm B4 (Bareilly) & $1.26 \%$ \\
\hline Farm B5 (Khatima) & $1.8 \%$ \\
\hline Farm B6 (Moradabad) & $4 \%$ \\
\hline
\end{tabular}

Table.3 Mortality due to coccidiosis at affected layer farms

\begin{tabular}{|l|c|}
\hline Farm Code & Mortality (\%) \\
\hline Farm L1(Uttarkashi) & $9.16 \%$ \\
\hline Farm L2(Pantnagar) & $14 \%$ \\
\hline Farm L3(Khatima) & $1.7 \%$ \\
\hline
\end{tabular}


The overall mortality rate in the coccidiosis affected farms during the study period was about $3.56 \%$. In broilers, it was around $3.1 \%$ whereas; in layers it was about $4.4 \%$. In one of the farm there was higher mortality due to concurrent infection with Infectious Bursal Disease (IBD). Banfield et al., (1999) estimated the total mortality rate of $6-10 \%$, Islam and Samad (2004) recorded 13.28\% mortality rate, Kinung'hi et al., (2004) observed $14.5 \%$ and $13.3 \%$ mortality rate in small and large farms, respectively, while Amer et al., (2010) found 3-12\% mortality rate and Yohannes et al., (2014) reported 5\% mortality rate in birds suffering from the clinical form of the disease. This variation in the mortality rates may be due to the amount of oocysts ingested, stock density, chemo prophylactic and chemotherapeutic drugs used and control measures adopted.

In conclusion, The epidemiological investigation revealed that the overall prevalence of coccidiosis was $56.25 \%$ with $60 \%$ (6 farms) in broiler flocks and $50 \%$ in layer farms (3 farms) with maximum prevalence during the month of Aug-Sep in broiler farms with $50 \%$ followed by JuneJuly and Dec-Jan with $33.3 \%$ and $16.6 \%$ respectively, while in layer farms there was an equal prevalence during June-July, AugSep and Oct-Nov with $33.3 \%$ each.

The management followed consisted mainly of deep litter system with $87.50 \%$, while $12.50 \%$ were reared under cage system. Among the different Eimeria species identified the most prevalent was E. tenella in broiler as well as in layer farms with $66.6 \%$ followed by E. maxima and E. necatrix in broiler farms with $50 \%$ and $33.3 \%$, while in layer birds E. maxima and E. acervulina with $33.3 \%$, respectively. The mortality rates were $3.1 \%$ and $4.4 \%$ for broilers and layers, respectively.

\section{References}

Adhikari, B., Gupta, R. and Pant, G. R. (2008). Prevalence and identification of coccidian parasite (Eimeria species) in layer chickens of Ratnanagar municipality, Chitwan district, Nepal. J. Nat. Hist. Mus., 23: 45-50

Amare, A., Mengistu, A. and Nazir, S. (2012). Prevalence and aetiology of poultry coccidiosis and associated risk factors in white leghorn grower chickens at Kombolcha poultry farm, Ethiopia. $J$. World's Poult. Res., 2(3): 54-59

Amer, M. M., Awaad, M. H. H., Khateeb, R. M. E., Eleez, M. T. N., Said, A. S., Ghetas, M. M. and Kutkat, M. A. (2010). Isolation and identification of Eimeria from field coccidiosis in chickens. J. Am. Sci., 6(10): 11071114

Bachaya, H. A., Raza, M. A., Khan, M. N., Iqbal, Z., Abbas, R. Z., Murtaza, S. and Badar, N. (2012). Predominance and detection of different Eimeria species causing coccidiosis in layer chickens. J. Anim. Plant Sci., 22(3): 597-600

BAHS. (2014). Basic Animal Husbandry and Fisheries Statistics. Government of India, Ministry of Agriculture, Department of Animal Husbandry, Dairying and Fisheries, Krishi Bhawan, New Delhi, India

Banfield, M. J., Kwakkel, R. P., Groeneveld, M., Doeschate R. A. H. and Forbes J. M. (1999). Effects of whole wheat substitution in broiler diets and viscosity on a coccidial infection in broilers. Br. Poult. Sci., 40: 58-60

Banu, S. S., Raman, M., Gomathinayagam, S., Dhinakar, R. G. (2009). Preponderance of Eimeria species in commercial poultry in Tamil Nadu. Indian J. Anim. Sci., 79: 164-166

Chauhan, H. V. S. and Sushovan, R. (2003). 
Poultry diseases, diagnosis and treatment. $2^{\text {nd }}$ ed. New International Ltd. Pub. 256p

Conway, D. P. and Mckenzie, M. E. (2007). Poultry coccidiosis- Diagnostic and testing procedure. $3^{\text {rd }}$ edition. Blackwell Publishing

Davou, G., Kumbish, P. R., Barde, I. J., Ahmed, J. S., Olabode, H. O. K. and Wungak, Y. S. (2015). A retrospective study on chicken coccidiosis in llorin, Kwara State, Nigeria. Direct Res. J. Agric. and Food Sci., 3(5): 93-97

Deo, B. G. (1988). The chemoprophylaxis of drug-resistant strains of Eimeria tenella in poultry. MVSc. Thesis. Rajendra Agriculture University, Bihar, India

Dinka, A. and Tolossa, Y. H. (2012). Coccidiosis in Fayoumi chickens at Debre Zeit agricultural research center poultry farm, Ethiopia. European Journal of Applied Sciences. 4(5): 191-195

FAO (1998). Village chicken production systems in rural Africa: Household food security and gender issues. FAO animal production and health paper 142. FAO, Rome, Italy, pp: 1-11

FAO (2015). Food and agriculture organization statistical division. http://www.faostat.org.

Gharekhani, J., Dehkordi, S. Z and Bahrami, M. (2014). Prevalence of coccidiosis in broiler chicken farms in Western Iran. J. Vet. Med., Article ID 980604. http://dx.doi.org/10.1155/2014/980604

Hadipour, M. M., Olyaie, A., Naderi, M., Azad, F. and Nekouie (2011). Prevalence of Eimeria species in scavenging native chickens of Shiraz, Iran. African J. Micro. Res., 5: 32963299

Islam, M. T. and Samad, M. A. (2004). Mortality in chicks associated with economic impact and prospect of layer chick rearer package programme of the participatory livestock development project in Bangladesh. Int. J. Poult. Sci., 3(2): 119-123

Jadhav B. N. and Nikam, S. V. (2014). Study of seasonal incidence of chicken coccidiosis in Gangapur and Vaijapur tehsil of Aurangabad district in Maharashtra. International Journal of Applied Science- Research and Review. 1(3): 93-97

Jatau, I. D., Sulaiman, N. H., Musa, I. W., Lawal, A. I., Okubanjo, O. O., Isah, I. and Magaji, Y. (2012). Prevalence of coccidian infection and Preponderance Eimeria species in free ranging indigenous and intensively managed exotic chickens during hot-wet season, in Zaria, Nigeria. Asian J. Poult. Sci. 6: $79-88$

Kala, S., Gattani, A., Kumar, A and Samantaray, S. (2013). Infectious dynamics of different species of Eimeria in chicken. Animal Science Reporter. 7: 139-145

Karthikeyan, R. and Neduncezhian, V. R. (2013). Vertical integration paving way to organised retailing in Indian Poultry Industry. International Journal of Business and Management Invention. 2(1): 39-46

Kinung'hi, S. M., Tilahun, G., Hafez, M. and Woldemeskel, M. (2004). Assesment of economic impact caused by poultry coccidiosis in small and large scale poultry farms in Debre Zeit, Ethiopia. Int. J. Poult Sci., 3(11): 715-718

Kumar, S., Garg, R., Ram, H., Maurya, P. S. and Banerjee, P. S. (2013). Gastrointestinal parasitic infections in chickens of upper gangetic plains of India with special reference to poultry coccidiosis. J. Parasit. Dis., 39 (1): 22-26

Long, P. L. and Reid, W. M. (1982). A guide for diagnosis of coccidiosis in 
chickens. Research report 404. University of Georgia, USA: college of Agriculture Experimental Stations. pp: $1-15$

Molla, B. and Ali, A. (2015). Epidemiological study on poultry coccidiosis: Prevalence, species identification and post mortem lesions in grower chicken in Kombolcha, North-Eastern Ethiopia. J. Vet. Med. Anim. Health., 7(1): $1-8$

Nikam, S. V., Jadhav, B. N. and Bhamre, S. N. (2012). Study of genus Eimeria (Eimeria mitis, Tyzzer 1929) in broiler chickens (Gallus gallus domesticus) from Aurangabad (M.S) India. Trends Parasitol. Res. 1(1): 39-41

Rath, P. K., Mandal, K. D. and Panda, P. (2015). Backyard poultry farming in India: a call for skill upliftment. Res. J. Recent. Sci., 4: 1-5

Rushton, J., Thornton, P. K. and Otte, M. J. (1999). Methods of economic impact assessment. Rev. Sci. Tec. Off. Int. Epiz., 18: 315-342

Sharma, S., Iqbal, A., Azmi, S. and Shah, H. A. (2013). Study of poultry coccidiosis in organized and backyard farms of Jammu region. Vet World.
6(8): 467-469

Shirley, M. W. (1995). Eimeria spp. and strains of chickens. Guidelines on Techniques in Coccidiosis Research. European Commission, Directorate General 12, Science Research and Development, Agriculture Biotechnology. pp: 1-34

Shirzad, M. R., Seifi, S., Gheisari, H. R., Hachesoo, B. A., Habibi, H. and Bujmehrani, H. (2011). Prevalence and risk factors for subclinical coccidiosis in Mazandaran province, Iran. Trop. Anim. Health Prod., 43: 1601-1604

Singh, L. J. and Meitei, N. M. (2015). Prevalence and intensity of infection of different Eimeria species in Broiler chicken, Gallus gallus domesticus from Imphal, Manipur, India. Indian J. Appl Res., 5(4): 817-819

Yohannes, A. T., Habtamu, M. T., Abreha, M. T. and Yisehak, R. T. (2014). ClinicPathological Study of Avian Coccidiosis and its economic Impact on small Scale Poultry Farming in Selected Districts of Tigray, Ethiopia. Asian J. Anim. Vet. Adv., 9: 674-682.

\section{How to cite this article:}

Sachin Pant, Prakash Bhatt, S. Shekhar and Gopal Krishna 2018. Epidemiological Investigation of Poultry Coccidiosis in and around Tarai Region of Uttarakhand. Int.J.Curr.Microbiol.App.Sci. 7(07): 374-380. doi: https://doi.org/10.20546/ijcmas.2018.707.046 